\title{
Prevalência e fatores associados à colonização retal e vaginal pelo estreptococo do grupo B em par- turientes e suas características fenotipicas
}

Prevalence of GBS genital colonization in pregnant women, risk factors associated with
this colonization and phenotypic characteristics

Autora: Valéria Moraes Neder Alves

Orientador: Prof. Dr. José Antonio Simões

Dissertação de Mestrado apresentada à Pós-graduação do Departamento de Tocoginecologia da Faculdade de Ciências Médicas (FCM) da Universidade Estadual de Campinas (UNICAMP), em 13 de abril de 2005.

Introdução: $\mathrm{O}$ estreptococo do grupo B (EGB) pode ser transmitido verticalmente e causar sérias conseqüências neonatais. No Brasil ainda não foram adotadas estratégias de prevenção e tratamento para reduzir a incidência de infecção neonatal pelo EGB, as quais, para serem efetivas, devem ser elaboradas com base em conhecimentos sobre a prevalência, os fatores associados ao maior risco de colonização e às características fenotípicas do EGB. Objetivo: estabelecer a prevalência da colonização pelo EGB no trato genital de parturientes, identificar os fatores associados a essa colonização e as características fenotípicas destes estreptococos. Método: foi realizado um estudo de corte transversal, no período de 11 de novembro de 2003 a 14 de maio de 2004. No momento da admissão para o parto, uma amostra de 316 parturientes do Hospital Universitário de Jundiaí foi submetida à coleta, com swab estéril, de material da região retal e vaginal, para detecção do EGB, por meio de cultura seletiva no meio de Todd-Hewitt. Dados referentes aos fatores associados à colonização foram obtidos dos prontuários rotineiramente preenchidos, ou perguntados às parturientes e transcritos para a ficha de dados. A susceptibilidade a sete antimicrobianos (penicilina, ampicilina, eritromicina, nitrofurantoina, clindamicina, cefalotina e gentamicina) foi obtida através da técnica de disco difusão dos antibióticos. As amostras foram diferenciadas pela tipagem sorológica e anti- soros tipo específicos, para os tipos sorológicos Ia, Ib, II, III, IV, V. Resultados: A prevalência da colonização pelo estreptococo do grupo B na amostra estudada foi de $14,6 \%$. Trabalhar fora de casa foi um fator significativamente associado à colonização. Nenhuma cepa foi resistente à penicilina, ampicilina, eritromicina e nitrofurantoína. A maior resistência foi para a gentamicina $(76,1 \%)$, seguida pela clindamicina $(17,4 \%)$. O sorotipo mais freqüente foi o Ib $(23,9 \%)$, seguido pelos sorotipos II e Ia $(19,6 \%$ e $17,4 \%$, respectivamente). Não houve correlação entre o sorotipo e a maior resistência antimicrobiana. Conclusões: a prevalência da colonização pelo EGB em parturientes do Hospital Universitário de Jundiaí foi alta. Não houve fatores associados à colonização, exceto ao que se refere ao fato de trabalhar fora de casa. A penicilina continua sendo a droga de escolha para a profilaxia intraparto, porém a clindamicina como alternativa em mulheres alérgicas à penicilina deverá ser melhor avaliada por antibiograma ou substituída pela cefalotina. O sorotipo mais freqüente (Ib) diferiu da maioria dos estudos em outros países, demonstrando a necessidade da identificação da sorotipagem em cada região, a fim de uma futura elaboração de vacinas específicas para nossas gestantes.

PALAVRAS-CHAVE: Estreptococo do grupo B; Gravidez; Antibiograma; Sorotipagem

Resumo de Tese

\section{Fatores de risco para neoplasia intra-epitelial cervical em pacientes submetidas à avaliação morfológica e pesquisa de DNA-HPV}

\section{Risk factors for intraepithelial cervical neoplasia in patients submitted to morphological evaluation and DNA-HPV determination}

Aluna: Terezinha Tenório da Silva

Orientador: Prof. Dr. Márcio Lobo Jardim

Co-orientador: Prof. Dr. Ricardo Arraes de Alencar Ximenes

Tese apresentada à Faculdade de Medicina da Universidade Federal de Pernambuco - UFPE - Recife (PE) - Brasil, para obtenção do Título de Doutor em Medicina Tropical, em 30 de outubro de 2004. Área de concentração: Doenças Infecciosas e Parasitárias

Resumo: Apesar da possibilidade do diagnóstico das lesões precursoras - neoplasias intra-epiteliais cervicais (NIC) - o câncer cervical invasivo ainda representa problema de saúde pública. Na última década, a maior descoberta sobre a etiologia da carcinogênese humana foi o reconhecimento de que o carcinoma cervical é uma rara conseqüência da infecção persistente por tipos oncogênicos de Papillomavirus humano (HPV). O desco- nhecimento da magnitude da associação entre HPV e NIC, numa região com elevada incidência da expressão clínica da infecção, motivou esta pesquisa. Com o objetivo principal de identificar os fatores de risco para NIC, realizou-se estudo tipo caso-controle, no qual foram incluídas 132 portadoras de NIC (casos) e 96 pacientes com colo normal (controles), atendidas no Setor de Colposcopia do Hospital das Clínicas da Universidade 
Federal de Pernambuco, no período de novembro de 2001 a agosto de 2002. O estudo teve aprovação do Comitê de Ética em Pesquisa da Instituição onde foi realizado. Os possiveis fatores de risco para NIC foram investigados por meio de formulário padronizado, aplicado a todas as pacientes, para pesquisa de idade, estado civil, grau de instrução, idade ao primeiro coito, número de gestações, número de parceiros sexuais, método contraceptivo utilizado, referência de DST anterior, soropositividade para HIV e tabagismo. Seguiram-se coletas de material para colpocitologia oncótica e para pesquisa de HPV por reação em cadeia da polimerase (PCRRFLP) com primers consensus MY09/MY11, exame colposcópico e biópsia com exame histopatológico, nos casos indicados. Para análise estatística de associação de NIC com os fatores de risco, utilizaram-se o odds ratio com intervalo de confiança e os testes qui quadrado e Fisher, em nivel de significância de 0,05. Para ajuste do efeito de cada uma das variáveis pelas demais, empregou-se a regressão logística pelo modelo backwards, testado com significância expressa pelo valor de $\mathrm{p}$ com grau de máxima verossimilhança. Para análise de concordância, aplicou-se o teste kappa. No modelo final de regressão múltipla, permaneceram as seguintes variáveis: a infecção por HPV de alto risco oncogênico $(\mathrm{OR}=$ 12,3 IC9 5\% 3,79-40,0), referência de DST anterior (OR
= 8,2 IC9 5\% 2,8-24,0), idade ao primeiro coito (OR = 4,0 IC9 5\% 1,7-9,3) e tabagismo (OR = 3,9 IC9 5\% 1,7-8,9). A soropositividade para HIV comportou-se como fator de proteção para NIC (OR = 0,04 IC95\% 0,01-0,13). Dentre as 78 amostras com positividade para HPV por PCRRFLP, houve predomínio de HPV16 ou variante 16 (46,9\% do grupo caso), com maior freqüência nas pacientes portadoras de lesões de alto grau. A análise dos aspectos morfológicos no diagnóstico da infecção cervical por HPV demonstrou que a colposcopia apresentou boa concordância com o exame histopatológico, em presença de positividade de DNA-HPV. Dentre os achados colposcópicos mais relevantes para o diagnóstico de lesões cervicais de alto grau e positividade de HPV, destacaram-se o epitélio acetobranco acentuado e mosaico áspero. Considerando os fatores de risco identificados no presente trabalho, concluiu-se que deve haver programas de rastreamento dos grupos com maior probabilidade de desenvolver NIC, por colpocitologia, colposcopia e histopatologia, associadas, quando possivel, à biologia molecular, prevenindo o surgimento do câncer invasor.

PALAVRAS-CHAVE: Neoplasia intra-epitelial cervical; Citodiagnóstico cervical; Citologia oncótica; Fatores de risco; Papillomavirus humano

Resumo de Tese

\title{
Prevalência de risco para fraturas estimado pela ultra-sonometria óssea de calcâneo em uma população de mulheres na menopausa residentes na ilha de Paquetá,RJ
}

\author{
Prevalence of the risk of fractures estimated by the quantitative ultrasound of the calcaneus \\ in a population of menopausal women who reside on the island of Paquetá, RJ
}

\author{
Autora: Patrícia Pereira de Oliveira \\ Orientadora: Profa. Dra. Lizanka Paola Figueiredo Marinheiro \\ Co-orientador: Ms Evandro Mendes Klumb
}

Dissertação de Mestrado apresentada à Pós-Graduação em Saúde da Criança e da Mulher do Instituto Fernandes Figueira/Fundação Oswaldo Cruz - FIOCRUZ - Rio de Janeiro (RJ) - Brasil, em 28 de fevereiro de 2005.

Introdução: observa-se uma forte tendência de envelhecimento da população mundial levando a um aumento da prevalência de doenças como a osteoporose e fraturas. A ultra-sonometria óssea (USO) surge como uma possibilidade para o rastreamento de grandes populações em Saúde Pública. Objetivos: determinar a prevalência de risco para fraturas estimado pela USO de calcâneo em uma população de mulheres na menopausa residentes na ilha de Paquetá/RJ. Metodologia: Realizamos questionário previamente estruturado, medidas antropométricas e USO de calcâneo com aparelho Sonost 2000 em 385 mulheres menopausadas após aprovação pelo Comitê de Ética em Pesquisa do Instituto Fernandes Figueira/Fiocruz. Resultados: a média de idade foi de 64,6 \pm 9,9 anos, com tempo médio de menopausa de 17,0 $\pm 10,7$ anos. Observamos que $59,2 \%$ da amostra apresentava $T$-score
$<-1$, sendo que 16,8\% apresentaram T-score $<-2,5$. Houve variação em todos os parâmetros do exame conforme o aumento da idade, e diferença significativa ( $\mathrm{p}$ $<0,05)$ entre os grupos de risco para fratura para idade, tempo de menopausa, peso, IMC e percentual de gordura corpórea. Houve correlação entre SOS e IMC $(\mathrm{r}=0,155 ; \mathrm{p}=0,002)$. As mulheres do grupo de maior risco $(T$-score $<-2,5)$ eram mais velhas, com maior peso e IMC do que as dos outros grupos. Conclusões: uma parcela importante da população feminina apresenta algum grau de risco para fraturas conforme avaliação da USO. Esta alteração foi significativamente relacionada com fatores clínicos e antropométricos.

PALAVRAS-CHAVE: Osteoporose; Epidemiologia; Fraturas; Calcâneo; Ultra-sonometria óssea 